\title{
A Novel Anionic Ring-Opening Polymerization of Potassium Salt of 4,4-Dimethyl-1,2-thiazetidin-3-one 1,1-Dioxide
}

\author{
Yoshio Imal, Mitsuru Ueda, and Kazuo OkuYama \\ Department of Polymer Chemistry, Faculty of Engineering, \\ Yamagata University, Yonezawa 992, Japan.
}

(Received February 16, 1978)

\begin{abstract}
KEY WORDS Anionic Ring-Opening Polymerization / 1,2-Thiazetidin3-one 1, 1-Dioxide / Poly(acylsulfonamide) /
\end{abstract}

While investigating ring-opening polyaddition using bifunctional nitrogen-containing four-membered heterocycles, ${ }^{1}$ it was necessary to obtain an unknown bifunctional $N$-acyl-1, 2-thiazetidin-3-one 1,1-dioxide which is expected to be one of the most reactive polymer-forming monomers for yielding polyamide derivatives. Attention was given to the fact that the reaction of potassium salt of 4 , 4-dimethyl-1,2-thiazetidin-3-one 1,1-dioxide (DMTD) with benzoyl chloride yielded no $N$ benzoyl derivative; the only product isolated was one having a carbonyl absorption at $1740 \mathrm{~cm}^{-1}$, believed to be due to polymeric DMTD through ring-opening polymerization. Investigation was then directed to the polymerization of this type of monomer. It was found that the potassium salt of DMTD readily underwent a ring-opening polymerization by use of $N$-phenylated DMTD as an initiator to give a high molecular weight poly(acylsulfonamide). This is perhaps the first example of a successful ring-opening polymerization of metal salt of heterocyclic compounds. This report presents a novel anionic ring-opening polymerization of potassium salt of DMTD under mild conditions.

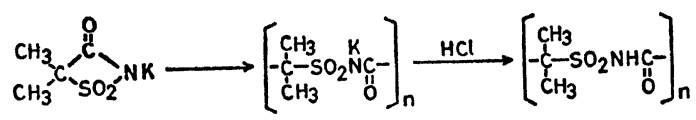

(1)

Prior to the monomer synthesis, 4, 4-dimethyl-1, 2-thiazetidin-3-one 1,1-dioxide (DMTD) was prepared in $74-\%$ yield by the reaction of ammonia with 2-chlorosulfonyl-2-methylpropionyl chloride, obtained from isobutyric acid, chlorosulfonic acid, and phosphoryl chloride. ${ }^{2}$ Recrystallization from chloroform-petroleum ether gave white needles, mp $149-151^{\circ} \mathrm{C}$ (lit. ${ }^{3} \mathrm{mp} 149-151^{\circ} \mathrm{C}$ ). IR (KBr): $1755 \mathrm{~cm}^{-1}\left(\nu_{\mathrm{c}=0}\right)$ and $1340,1160 \mathrm{~cm}^{-1}$ $\left(\nu_{\mathrm{SO}_{2}}\right)$.

The polymer-forming monomer, potassium salt of DMTD (DMTD-K salt), was synthesized with an $81-\%$ yield by reacting DMTD with potassium hydroxide in ethanol. The white leaflets melted at $251^{\circ} \mathrm{C}$ with decomposition (by DTA). IR (KBr): $1690 \mathrm{~cm}^{-1}\left(\nu_{\mathrm{C}=0}\right)$ and $1240,1150 \mathrm{~cm}^{-1}$ $\left(\nu_{\mathrm{SO}_{2}}\right)$.

Anal. Calcd for $\mathrm{C}_{4} \mathrm{H}_{6} \mathrm{NO}_{3} \mathrm{SK}: \mathrm{C}, 25.66 ; \mathrm{H}$, 3.23; N, 7.48. Found: C, 25.7; H, 3.4; N, 7.3.

The initiator, $N$-phenylated DMTD, was synthesized with a $66-\%$ yield by the condensation of 2-chlorosulfonyl-2-methylpropionyl chloride with aniline. It was recrystallized from hexane to give white needles, $\mathrm{mp} 43-45^{\circ} \mathrm{C}$. IR $(\mathrm{KBr}): 1760 \mathrm{~cm}^{-1}$ $\left(\nu_{\mathrm{C}=\mathrm{o}}\right)$ and $1340,1180 \mathrm{~cm}^{-1}\left(\nu_{\mathrm{so}_{2}}\right)$.

Anal. Calcd for $\mathrm{C}_{10} \mathrm{H}_{11} \mathrm{NO}_{3} \mathrm{~S}: \mathrm{C}, 53.32 ; \mathrm{H}$, 4.92; N, 6.22. Found: C, 53.3; H, 5.0; N, 6.1.

The ring-opening polymerization of DMTD-K salt was carried out using $N$-phenylated DMTD in tetramethylene sulfone (TMS) at room temperature. The following example is typical of the polymerization experiments. To a solution of $0.467 \mathrm{~g}(2.5 \mathrm{mmol})$ of DMTD-K salt in $5 \mathrm{ml}$ of TMS was added $5.5 \mathrm{mg}(0.025 \mathrm{mmol})$ of $N$-phenylated DMTD, and the mixture was stirred at room temperature for $5 \mathrm{hr}$. The solution became turbid as the polymerization proceeded. The 
polymer was isolated by pouring the mixture into $200 \mathrm{ml}$ of diluted hydrochloric acid. It was filtered, washed thoroughly with water, and dried. The fibrous white polymer weighed $0.367 \mathrm{~g}(97 \%)$, and had an inherent viscosity of 4.95 in $N, N$ dimethylacetamide (DMAc), measured at a concentration of $0.5 \mathrm{~g} / \mathrm{d} l$ at $30^{\circ} \mathrm{C}$. IR $(\mathrm{KBr}): 3270$ $\mathrm{cm}^{-1}\left(\nu_{\mathrm{N}-\mathrm{H}}\right), 1740 \mathrm{~cm}^{-1}\left(\nu_{\mathrm{C}=0}\right)$, and 1340,1180 $\mathrm{cm}^{-1}\left(\nu_{\mathrm{SO}_{2}}\right)$.

Anal. Calcd for $\mathrm{C}_{4} \mathrm{H}_{7} \mathrm{NO}_{3} \mathrm{~S}: \mathrm{C}, 32.20 ; \mathrm{H}$, $4.73 ; \mathrm{N}, 9.39$. Found: $\mathrm{C}, 32.0 ; \mathrm{H}, 4.8 ; \mathrm{N}, 9.3$.

The formation of poly(acylsulfonamide) was confirmed by infrared spectroscopy and elemental analyses. Figure 1 shows the infrared spectrum on $\mathrm{KBr}$ pellet.

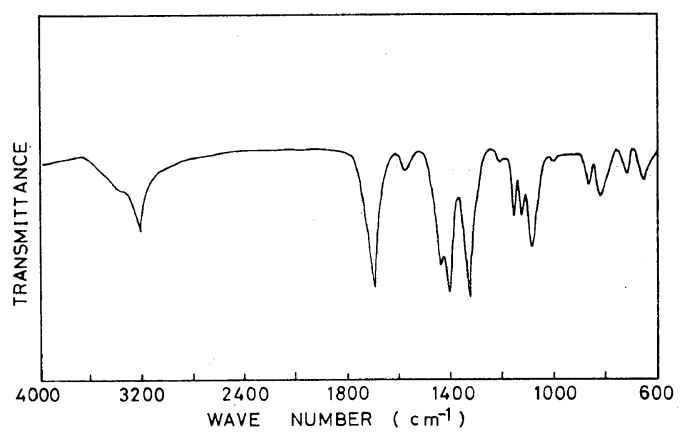

Figure 1. Infrared spectrum of poly(acylsulfonamide).

Table I. Ring-opening polymerization of DMTD-K salt in TMS

\begin{tabular}{|c|c|c|c|c|}
\hline \multicolumn{3}{|c|}{$\begin{array}{l}\text { Polymerization } \\
\text { conditions }^{\mathrm{a}}\end{array}$} & \multicolumn{2}{|c|}{ Polymer } \\
\hline $\begin{array}{l}\text { Amount of } \\
\text { initiator, } \\
\text { mol \% }\end{array}$ & $\underset{{ }^{\circ} \mathrm{C}}{\mathrm{Temp}}$ & $\underset{\mathrm{hr}}{\text { Time }}$ & $\underset{\%}{\text { Yield, }}$ & $\eta_{\text {inh }}{ }^{b}$ \\
\hline 0.7 & 20 & 0.5 & 25 & 3.86 \\
\hline 1.2 & 20 & 0.5 & 86 & 5.70 \\
\hline 2.0 & 20 & 0.5 & 87 & 5.28 \\
\hline 2.7 & 20 & 0.5 & 88 & 3.13 \\
\hline 1.0 & 20 & 5 & 97 & 4.95 \\
\hline 1.0 & 40 & 5 & 98 & 4.70 \\
\hline 1.0 & 60 & 5 & 95 & 4.37 \\
\hline 1.0 & 80 & 5 & 95 & 3.94 \\
\hline 1.0 & 100 & 5 & 98 & 4.03 \\
\hline
\end{tabular}

a) Polymerization was carried out with $2.5 \mathrm{mmol}$ of the monomer in $5 \mathrm{ml}$ of TMS using $N$-phenylated DMTD as the initiator.

b) Measured at a concentration of $0.5 \mathrm{~g} / \mathrm{d} l$ in DMAc at $30^{\circ} \mathrm{C}$.
In the absence of initiator, no polymer was produced even after the solution of DMTD-K salt in TMS was maintained at $100^{\circ} \mathrm{C}$ for $24 \mathrm{hr}$. The results of this polymerization are summarized in Table I. Figure 2 shows the rate of the polymerization in terms of yield and inherent viscosity of the resulting polymer. The ring-opening polymerization of DMTD-K salt is characterized by a rapid conversion in TMS even at room temperature. The monomer was consumed steadily in the early stage of the polymerization, and a high molecular weight polymer was formed at once with little change in molecular weight throughout the polymerization. These results are essentially compatible with the distinguishing feature of chainpolymerization mechanism.

As can be seen from Table I, the best results were obtained when the initiator was used at a concentration above $1 \mathrm{~mol} \%$ based on the amount of monomer for the production of a high molecular weight polymer. Although the polymerization temperature was not so critical over a wide temperature range $\left(20-100^{\circ} \mathrm{C}\right)$, the molecular weight tended to decrease to some extent by raising the temperature. Under satisfactory polymerization conditions, the polymer having inherent viscosity as high as 5.7 was readily obtained in almost quantitative yield.

These facts indicate that the ring-opening polymerization of DMTD-K salt probably proceeds

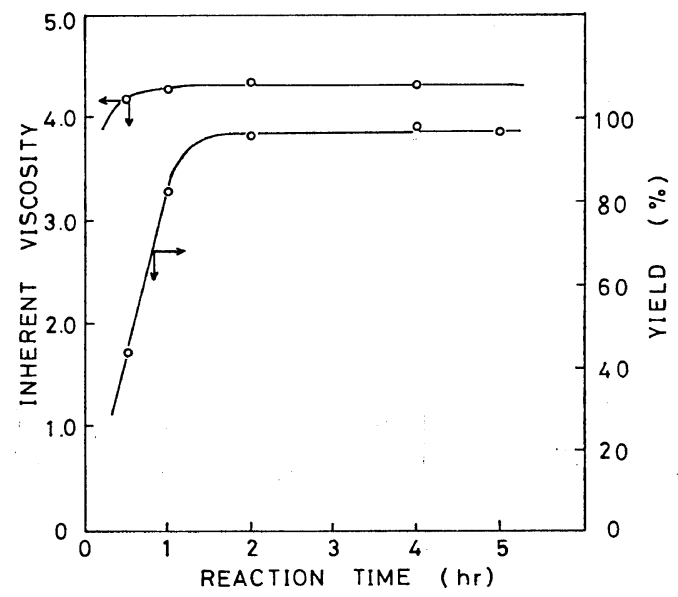

Figure 2. Ring-opening polymerization of DMTD$\mathrm{K}$ salt in TMS at $20^{\circ} \mathrm{C}$ in the presence of the $N$-phenylated DMTD initiator $(0.5 \mathrm{~mol} \%)$. 

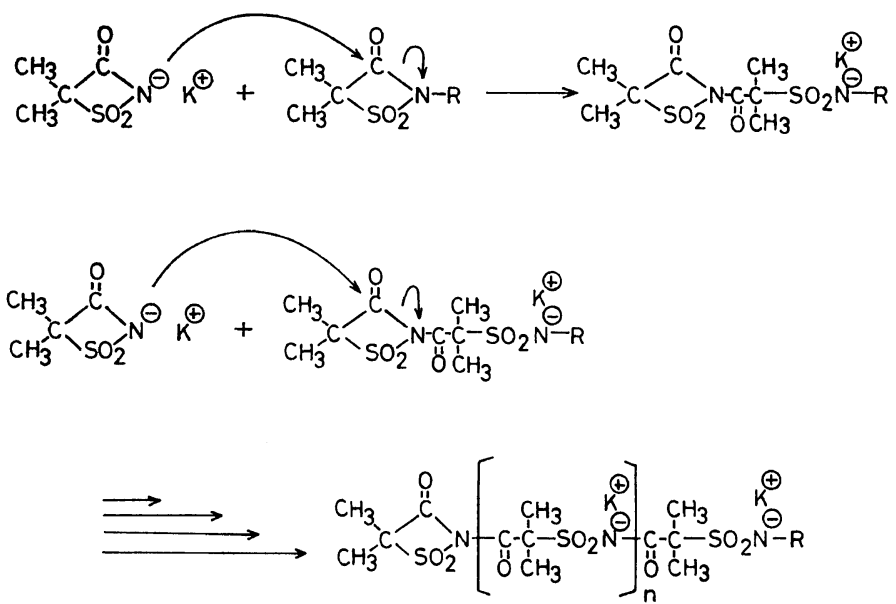

through an anionic polymerization mechanism analogous to that proposed for the anionic fast polymerization of various lactams. ${ }^{4,5}$ The essential feature of this mechanism is the attack of the cyclic imide anion on the reactive acyl imide end, as shown in eq 2 . It is worth noting that the anionic polymerization of this type of monomer differs in mechanism from that of lactams; in the latter, the anion is not on the growing chain but on the monomer.

Thus, the high polymerizability of DMTD-K salt may be attributed to its highly strained fourmembered ring structure, as is the case with other four-membered heterocycles such as 2azetidone $^{6}$ and ethanesultam. ${ }^{7,8}$

Detailed studies of the anionic ring-opening polymerization and properties of the resulting poly(acylsulfonamide) will be reported on in later papers.
Acknowledgment. The authors are indebted to Mr. Sadao Kato for the elemental analyses.

\section{REFERENCES}

1. Y. Imai and H. Hirukawa, Polym. J., 4, 93 (1973).

2. A. Le Berre, A. Etienne, J. Coquelin, and C. Jacquot, Bull. Soc. Chim. Fr., 1973, 210.

3. B. J. R. Nicolaus, E. Bellasio, and E. Testa, Helv. Chim. Acta, 45, 717 (1962).

4. H. K. Hall, Jr., J. Am. Chem. Soc., 80, 6404, 6412 (1958).

5. O. Wichterle, J. Sebenda, and J. Kralicek, Fortsch. Hochpolym. Forsck., 2, 578 (1961).

6. R. Graf, G. Lohaus, K. Boerner, E. Schmidt, and H. Bestian, Angew. Chem., 74, 523 (1962).

7. Y. Imai and H. Hirukawa, J. Polym. Sci., Polym. Lett. Ed., 11, 271 (1973).

8. Y. Imai, H. Hirukawa, and M. Ueda, Kobunshi Ronbunshu, 31, 755 (1974). 